\title{
The ultrasound effect on the morphological properties of hydroxyapatite
}

\author{
Konstantin Chuprunov ${ }^{1}$, Eugenii Kolesnikov ${ }^{1}$, Igor Ilinykh ${ }^{1}$, Andrey Yudin ${ }^{1}$, Denis Leybo ${ }^{1}$, and \\ Gopalu Karunakaran ${ }^{2}$ \\ ${ }^{1}$ National University of Science \& Technology "MISIS", Department of Functional Nanosystems and High-Temperature \\ Materials, 4, Leninsky avenue, Moscow 119049, Russia \\ ${ }^{2}$ Seoul National University of Science and Technology, Department of Fine Chemistry, 232 Gongneung-ro, Nowon-gu, \\ 01811, Seoul, Korea
}

\begin{abstract}
The present study considers the morphological and dispersity characteristics of hydroxyapatite (HAp) samples synthesised through the ultrasound-assisted hydrothermal method with additional pressure treatment. The samples were analyzed by the $\mathrm{X}$ - Ray diffraction, scanning electron microscopy, low-temperature nitrogen adsorption. The ultrasound effect on the HAp morphologiy and dispersity was studied. The pressure assisted ultrasonic treatment made possible obtaining HAp samples with different morphology from rods and flakes to particles with irregular shape close to spherical. Also pressure assisted ultrasonic treatment able to increase the porosity of HAp materials.
\end{abstract}

\section{Introduction}

Hydroxyapatite (HAp)-based materials are widely used due to their physical and chemical properties. Furthermore, the mechanical properties of these materials [1] attract interest for their applications as biocompatible material in drug delivery [2,3], 3d tissue scaffold printing [4,5] and bone filling [6,7]. HAp is broadly used in medicine to prepare bone and tooth implants due to its ability to actively bind with healthy bone tissue without any adverse consequences because of their crystallographic and chemical similarity [8,9]. Regarding its physical and chemical properties, dispersity, morphology and specific surface area appear to be rather important parameters [10]. Controlling them during the HAp synthesis may affect the HAp physical and chemical properties.

HAp is usually synthesized through the hydrothermal procedure [11-15]. To increase the intensity of the synthesis process, the ultrasound-assisted treatment technology can be effectively implemented. In [16], the authors demonstrate changes in the morphology of HAp samples after using ultrasound.

Considering the aforementioned, the aim of the present work was to study the Hap samples obtained through the novel ultrasound-assisted hydrothermal treatment and describe the ultrasound effect on the HAp morphological and dispersity characteristics.

\section{Materials and methods}

\subsection{Materials}

Calcium nitrate tetrahydrate $\left(\mathrm{Ca}\left(\mathrm{NO}_{3}\right)_{2} \bullet 4 \mathrm{H}_{2} \mathrm{O}\right) \quad \mathrm{AR}$ Grade and diammonium hydrogen phosphate $\left(\left(\mathrm{NH}_{4}\right)_{2} \mathrm{HPO}_{4}\right)$ AR Grade were used as initial precursors. Ammonium hydroxide $\left(\mathrm{NH}_{4} \mathrm{OH}\right)$ was used to vary the $\mathrm{pH}$ level. The distilled water was used as a solvent. All the reagents were acquired from Reachem (Russia).

\subsection{Synthesis procedure}

HAp samples were synthesized through the ultrasoundassisted hydrothermal method. First, 10-wt.\% distilled water calcium nitrate, diammonium hydrogen phosphate and ammonium hydroxide solutions were prepared. The $100 \mathrm{ml}$ solution $\mathrm{Ca}\left(\mathrm{NO}_{3}\right)_{2}$ solution was added stepwise to the $\left(\mathrm{NH}_{4}\right)_{2} \mathrm{HPO}_{4}$ solution, with rapid mixing at $300 \mathrm{rpm}$ using a Heidolph RZR 2051 stirrer (Germany) at room temperature. The $\mathrm{Ca} / \mathrm{P}$ ratio was kept stoichiometrically stable at 1.67 . Then, the $\mathrm{pH}$ level in the reactor was increased up to 11 using $\mathrm{NH}_{4} \mathrm{OH}$. Two sample groups were obtained. The first one was dried during $2 \mathrm{~h}$ at a temperature of $65^{\circ} \mathrm{C}$ in a SNOL drying box (Lithuania), whereas the second one was treated using a Hielscher UIP $1000 \mathrm{HD}$ ultrasonic generator (Germany) at a volume $100 \mathrm{~mL}$ during 0,30 and $60 \mathrm{~min}$ at temperature $70{ }^{\circ} \mathrm{C}$ with or without pressure application. The pressure in the systems was provided by 
a pneumatic compressor. It was kept stable at the level of 2.5 bar. Table 1 reports the nomenclature and experimental conditions of the produced samples.

Table 1. HAp samples obtained via the hydrothermal technique

\begin{tabular}{ccc}
\hline Sample & $\begin{array}{c}\text { Ultrasonic } \\
\text { treatment } \\
\text { duration, min }\end{array}$ & Pressure, bar \\
HAp\#1 & 0 & 0 \\
HAp\#2 & 60 & 0 \\
HAp\#3 & 30 & 2.5 \\
HAp\#4 & 60 & 2.5 \\
\hline
\end{tabular}

\subsection{Characterization studies}

The phase composition of the HAp samples studied by the X-RAY diffraction analysis using a Scientific Instruments Difray 401 device (Russia) in the range $14-$ $140^{\circ} 2 \theta$, with the interval $58^{\circ}$, and residual time 300 sec. The crystallinity calculated with equation 1 . The $\mathrm{V}_{112 / 300}$ was the minimum of intensity between two intensity peaks reflected from the planes (112) and (300) consequently. The $\mathrm{I}_{300}$ was the maximum intensity for the plane (300). $\mathrm{X}_{\mathrm{c}}$ was crystallinity degree [17].

$$
c=1-\frac{\mathrm{V}_{112 / 300}}{\mathrm{I}_{300}}
$$

The HAp morphological properties were investigated with a scanning electron microscopy (SEM) Tescan Vega 3 instrument (The Czech Republic). The samples placed on the graphite scotch. The particle size distribution analyzed with iTEM Olympus software. 1000 particles study for each samples to demonstrate average particle size. Standard deviation calculated with Microsoft Excel. The specific surface area by BrunauerEmmett-Teller (BET) and the pore size by density functional theory (DFT) were analyzed using lowtemperature nitrogen adsorption on a Quantachrome Nova 1200 e device (USA). The samples placed in quartz cell and degasify under vacuum during 8 hours. The specific surface area analyzed in interval $0.05-0.3$ relative pressure. The pore volume and pore size distribution measured in a range $0.05-0.95$ relative pressure. The average particle size using BET calculated with equation $2[18,19]$.

$$
d=6 / \rho \cdot S
$$

where, $\mathrm{S}$ - was specific surface area, $\rho$ - was theoretical density, d - was the average particle size also was estimated the primary spherical shape and same diameter size.

\section{Results and discussion}

Figure 1 demonstrates X-ray diffraction (XRD) patterns of the HAp samples synthesized. They indicate that all the samples consist of the HAp crystalline phase, and the ultrasonic treatment has no effect on the HAp phase composition. All $2 \theta$ values compared with the standard JCPDS card (09-0432) of hydroxyapatite.

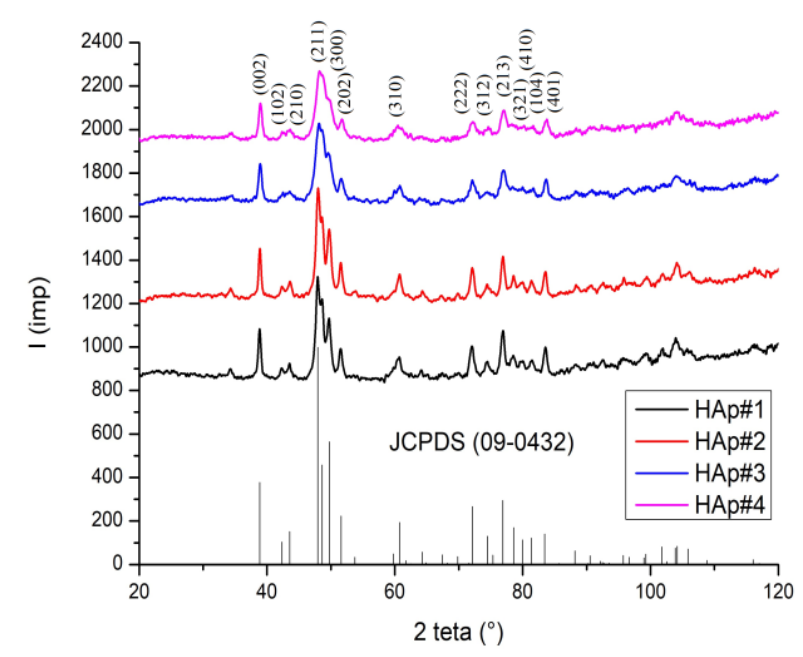

Fig. 1. HAp X-Ray patterns

Table 2 presented the calculated crystallinity degree of the HAp samples.

Table 2. The HAp samples crystallinity degree

\begin{tabular}{lllll}
\hline $\begin{array}{l}\text { Sample } \\
\begin{array}{l}\text { Crystallinity } \\
\text { degree, } \%\end{array}\end{array}$ & 17 & 25 & 4 & Hap\#1 \\
\hline
\end{tabular}

The ultrasonic treatment made possible obtaining HAp samples with low crystallinity degree. The additional pressure treatment during sonication process decrease crystallinity degree to $0 \%$ after $60 \mathrm{~min}$ ultrasonic treatment with pressure 2.5 bar.

The HAp morphology is different for the samples obtained with and without pressure applied during the ultrasonic processing. The HAp\#1 sample consists of agglomerates with an average size close to $1-2 \mu \mathrm{m}$, as shown in Figure 2a,b. The agglomerates are composed of nanosized rods. The 60-min ultrasound-assisted treatment without pressure application provided a decrease in the agglomerate average size of $0.5 \mu \mathrm{m}$ (Figure 2c,d). The ultrasonic treatment used to increase the homogenization and dispergation effects due to high intensity oscillation. The pressure of 2.5 bar applied during the ultrasound-assisted treatment altered the morphology of the HAp\#3 and HAp\#4 samples. The HAp\#3 sample consists of agglomerates with an average size of 2-3 $\mu \mathrm{m}$. The shape of agglomerated particles is irregular, close to spherical (Figure 2e,f). The morphology of the HAp\#4 (Figure $2 \mathrm{~g}, 2 \mathrm{~h}$ ) sample is almost similar to that of the HAp\#3 sample, but the ultrasound-assisted treatment with the pressure applied resulted in increasing the agglomerate average size from 2-3 up to 5-7 $\mu \mathrm{m}$. Standard deviation calculated with Microsoft Excel was $0.5 \mu \mathrm{m}$ 


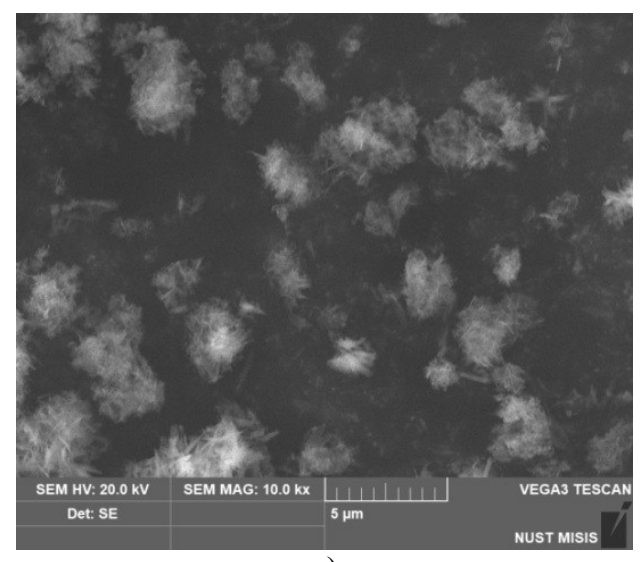

a)

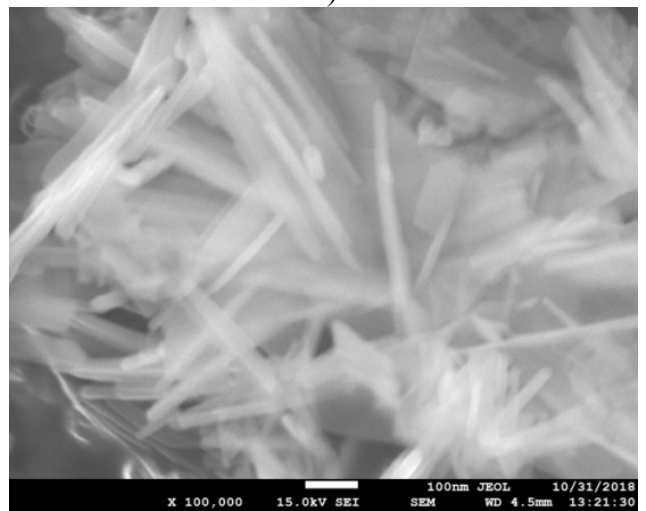

b)

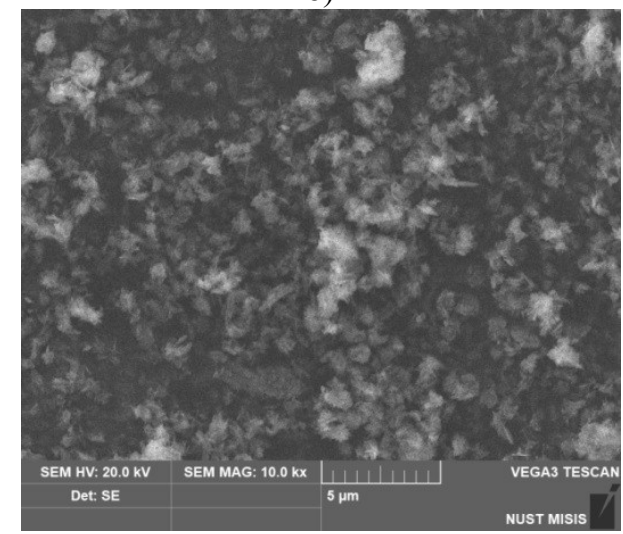

c)

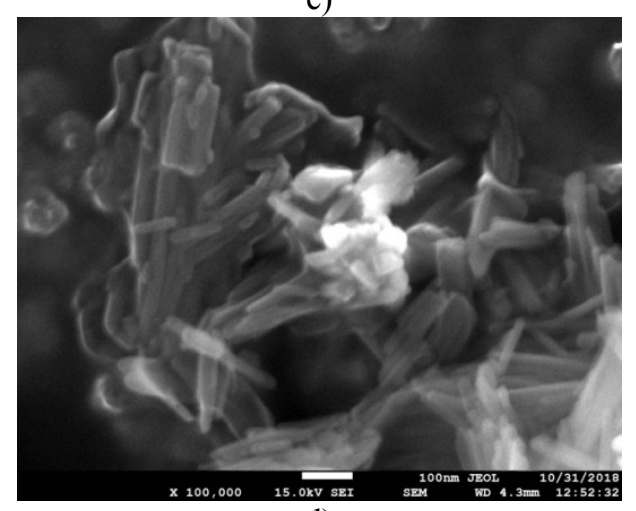

d)

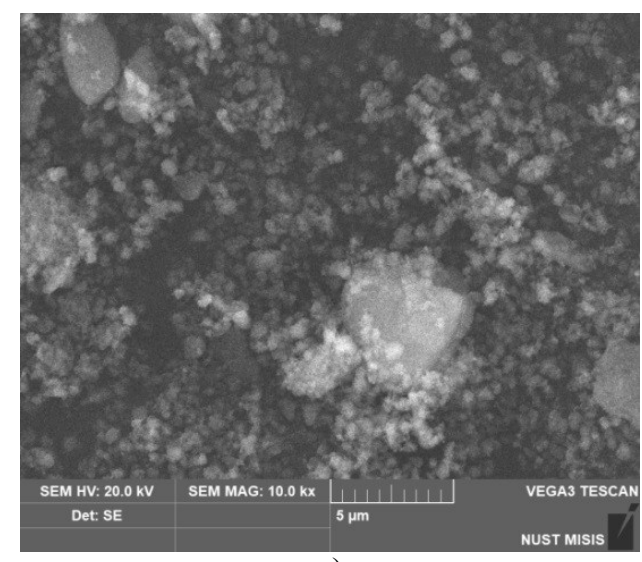

e)

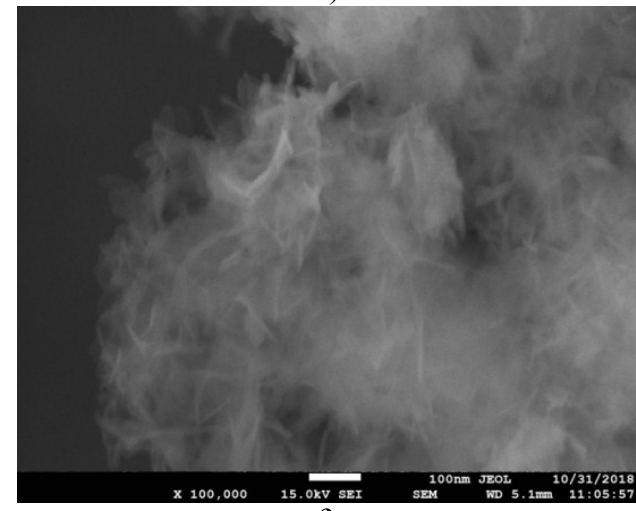

f)

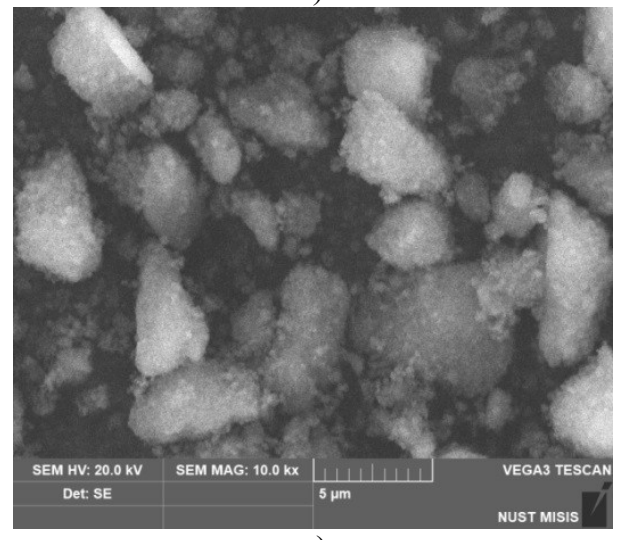

g)

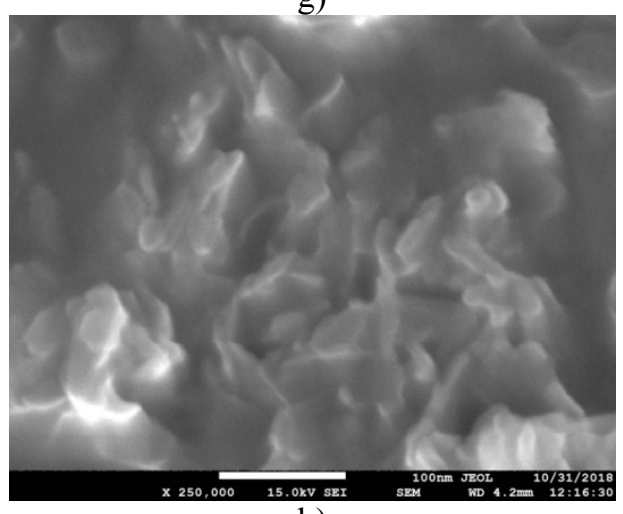

h)

Fig.2. SEM micrographs of the samples: a), b) HAp\#1, c), d) HAp\#2, e), f) HAp\#3, and g), h) HAp\#4 


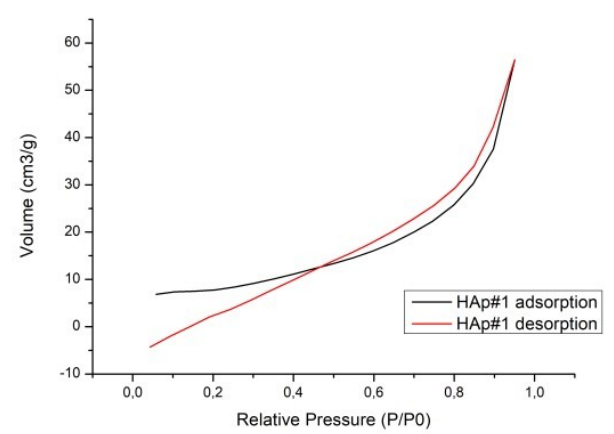

a)

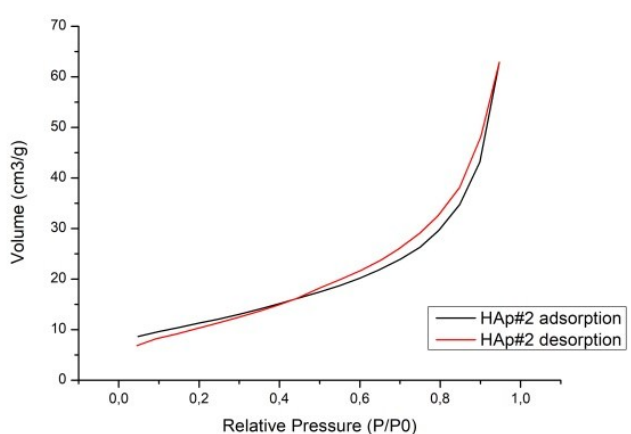

b)

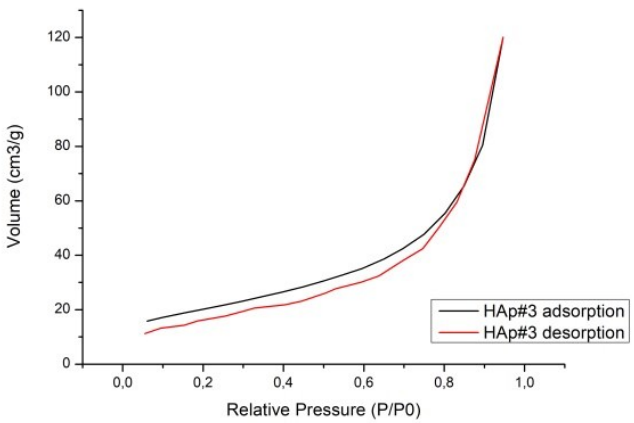

c)

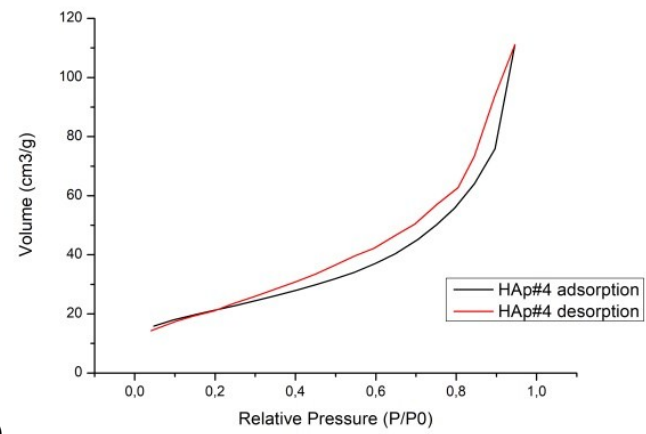

d)

Fig.3. Hysteresis loops: a) HAp\#1, b) HAp\#2, c) HAp\#3, and d) Hap\#4; pore volume: e) adsorption, and f) desorption; pore size distribution: g) adsorption, and h) desorption

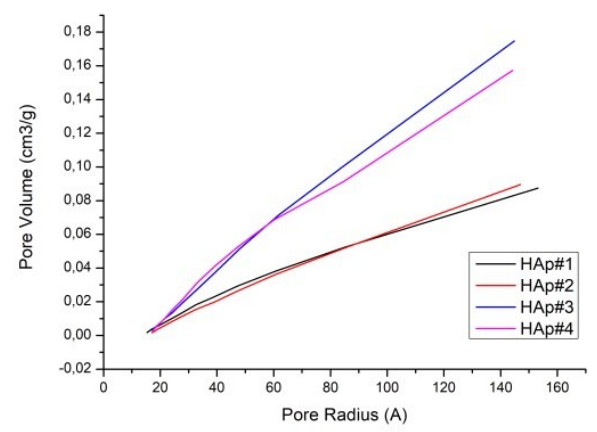

e)

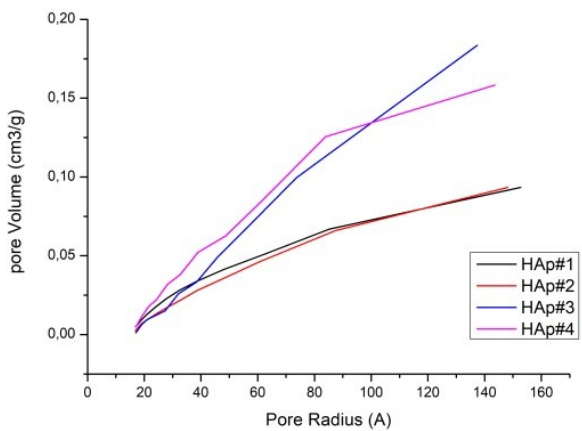

f)

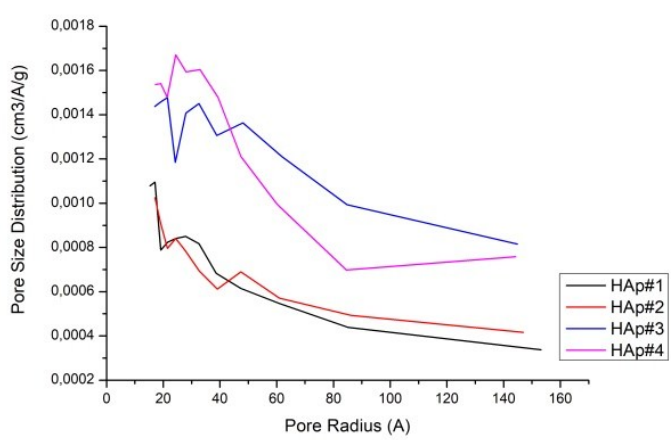

g)

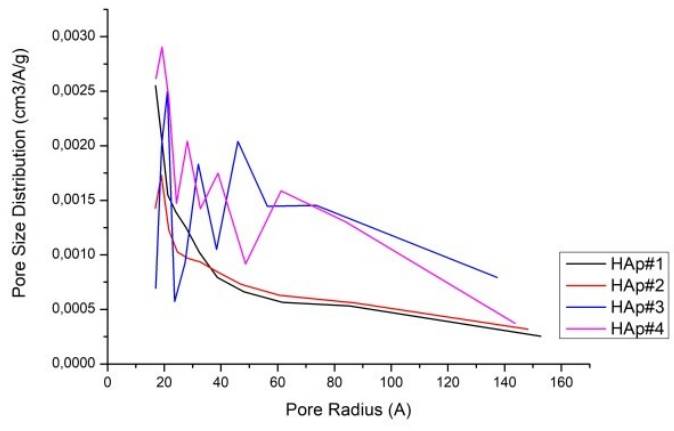

h) 
Figure 3 shows the low-temperature nitrogen adsorption/desorption isotherms, as well as the pore volume and pore size distribution. The physisorption isotherms can be divided into six groups. The shape of the adsorption/desorption hysteresis loops characterizes porous features of the materials. For all the samples, the hysteresis loops can be attributed to the capillary condensation of gas in the mesoporous structure (Figures 3a-d). The total pore volume calculated using the adsorption/desorption hysteresis loops data demonstrates that the pressure application during the ultrasoundassisted treatment leads to a 3-fold increase in the total pore volume for the HAp\#3 and HAp\#4 samples in comparison with the HAp\#1 and HAp\#2 samples (Figure $3 \mathrm{e}, \mathrm{f}$ ). From the pore size distribution (Figure $3 \mathrm{~h}, \mathrm{~g}$ ), it can be seen that the maximum pore volume is reached for pores with a radius of $1-6 \mathrm{~nm}$.

The values of the BET specific surface area of the HAp\#1, HAp\#2, Hap\#3 and HAp\#4 samples and the average particle size calculated according to equation (1) are presented in Table 2.

As can be observed, the specific surface area of the HAp\#1 and HAp\#2 samples obtained without pressure application is $24 \mathrm{~m} 2 / \mathrm{g}$, and the average particle size relevant with the specific surface area is $79 \mathrm{~nm}$ (Table 3). The pressure application during the ultrasound-assisted treatment made it possible to increase the surface area up to 43 and $46 \mathrm{~m} 2 / \mathrm{g}$, respectively, and to decrease the average particle size down to 44 and $41 \mathrm{~nm}$, respectively (HAp\#3 and HAp\#4).

Table 3. Specific surface area (SSA) and particle size (D) values obtained for the HAp samples

\begin{tabular}{ccccc}
\hline Samples & HAp\#1 & HAp\#2 & HAp\#3 & HAp\#4 \\
SSA, m $\mathbf{~} / \mathbf{g}$ & $24 \pm 2$ & $24 \pm 2$ & $43 \pm 4$ & $46 \pm 5$ \\
D, nm & 79 & 79 & 44 & 41 \\
\hline
\end{tabular}

The changes in the morphology correlate with the changes in the porous structure. The agglomerates demonstrate highly porous structure with increasing their average size after applying the pressure during the ultrasound-assisted treatment procedure. The ultrasonic treatment provides homogenization effect and the pressure at the system supposed to increase the average agglomerate size.

\section{Conclusion}

The novel ultrasound-assisted hydrothermal synthesis of HAp with pressure application makes it possible to alter the morphology and porous structure of the material obtained. The ultrasound treatment without pressure application results in the needle-like morphology of the HAp samples, whereas the pressure of 2.5 bar applied changes the morphology from needle-like to irregular in shape, close to spherical. Moreover, the pressure application increases the total pore volume 3-fold for the HAp samples.

The work funded by the Ministry of Science and Higher Education (formerly, the Ministry of Education and Science) of the Russian Federation under Project No. RFMEFI57517X0168.

\section{References}

1. E. Torres, V. Fombuena, A. Vallés-Lluch, T. Ellingham, Materials Science and Engineering: $C$, 75, 418 (2017)

2. M. Vallet-Regi, D.A. Arcos, RSC Publishing (Cambridge, United Kingdom 2008)

3. T. Kokubo, Woodhead Publishing Limited, (Cambridge 2008)

4. S. Huiping, Ceramic International, In press, https://doi.org/10.1016/j.ceramint.2018.09.300

5. M. Okada, T. Furuzono, Sci. Technol. Adv. Mater. 13, (2012)

6. S.V. Dorozhkin, Acta Biomater. 6, 715 (2010)

7. Y. Hong, H. Fan, B. Li, B. Guo, M. Liu, X. Zhang, Mater. Sci. Eng. 70, 225 (2010)

8. Cationic and anionic substitutions in hydroxyapatite, In: Handbook of Bioceramics and Biocomposites, 145 (2016)

9. M. Mohan, Materials Science and Engineering: $C$, 92, 329 (2018)

10. G.S. Kumar, G. Karunakaran, E.K. Girija, E. Kolesnikov, N.V. Minh, M.V. Gorshenkov, D. Kuznetsov, Cer. Inter. 44, 11257 (2018)

11. Okada M., Omori Y., Awata M., Shirai T., Matsumoto N., Takeda S., Furuzono T., J. Nanopart. Res. 16, 2469 (2014)

12. Lee W.- H., Zavgorodniy A.V., Loo C.- Y., Rohanizadeh R. J. Biomed. Mater. Res. Part A, 100A 1539 (2012)

13. Jinawath S., Polchai D., Yoshimura M. Mater. Sci. Eng. C. 22, 35 (2002)

14. Zhang G., Chen J., Yang S., Yu Q., Wang Z., Zhang Q., Mater. Lett. 65572 (2011)

15. Smolen D., Chudoba T., Malka I., Kedzierska A., Lojkowski W., Swieszkowski W., Kurzydlowski K.J., Kolodziejczyk-Mierzynska M., LewandowskaSzumiel M., Int. J. Nanomedicine. 8, 653 (2013)

16. S.S. Selvaraj J. Samuel J.R. Vijay Solomon P. Wilson, Col. and Surf. A: Physicochemical and Engineering Aspects 538, 270 (2018)

17. Cacciotti I. J. Eur. Ceram. Soc. 29, 2969 (2009)

18. Bianco A. Mater. Res. Bull. 44, 345 (2009)

19. Bianco A. Cer. Inter. 36, 313 (2010) 